\title{
IMPACT OF AMOEBIASIS AND GIARDIASIS ON TRACE ELEMENTS AMONG EGYPTIAN CHILDREN
}

\author{
BY \\ AHMED M. S. BAYOUMY ${ }^{1^{*}}$, MOSTAFA E. MOSTAFA ${ }^{2}$, \\ MOHAMED S. FARAMAWY ${ }^{1}$ AND WAFAA F. A. AHMED ${ }^{3}$ \\ Departments of Medical Parasitology, Faculties of Medicine Al-Azhar University, \\ (Cairo ${ }^{1}$ and Damietta ${ }^{2}$ ) and Department of Biological and Environmental Sciences ${ }^{3}$, \\ Faculty of Home Economics, Al-Azhar University, Tanta, Egypt \\ ('Correspondence: drahmedbayoumy@azhar.edu.eg)
}

\begin{abstract}
Giardia lamblia and Entamoeba histolytica are protozoan parasites causing marked morbidity in Egyptian children. A case-control random study was conducted from September to January 2020 and included 49 children (1-18 years) attending Al Hussein University Hospital, Cairo, Egypt. They had amoebiasis (30 cases) and giardiasis (19 cases) and considered as the study group. Another 50 healthy persons were considered as a control group. All cases were subjected to the estimation of serum levels of Zinc, Copper, and Iron.

Serum Zinc level was significantly decreased in the infected group than the control group. The mean and standard deviation in the study group was $66.83 \pm 8.60$ (amoebiasis was $65.64 \pm 8.26 \&$ giardiasis was $68.71 \pm 9.01$ ) compared to the control group $95.67 \pm 8.34$. Serum Copper was significantly increased in infected group than control group. The mean and standard deviation was $129.93 \pm 19.45$, for the amoebiasis was $130.63 \pm 20.17$ and giardiasis was $128.81 \pm 18.76$ as compared to the control group $85.07 \pm 6.29$.

Serum Iron level was significantly decreased in the infected group than the control group. The mean and standard deviation in the study group was $50.63 \pm 5.23$ (amoebiasis was $49.96 \pm 5.61 \&$ giardiasis was 51.69 \pm 4.50 ) compared to the control group 82.87 \pm 9.28 .
\end{abstract}

Keywords: Children, Amoebiasis, Giardiasis, Trace elements

\section{Introduction}

Giardia lamblia and Entamoeba histolyti$c a$ are protozoan parasitic agents that significantly cause diarrheal disease morbidity in developing countries including Egypt (Charles et al, 2004). Giardia lamblia is a flagellate that inhabits the gut lumen in close association with enterocytes. It is a major cause of malabsorptive diarrheal disease throughout the world mainly in children younger than 10 years with peak prevalence rates of $15-20 \%$ (Pennardt et al, 2008).

Entamoeba histolytica is an amoeba that preferentially inhabits the mucosal region of the gut lumen, and under certain circumstances becomes invasive, and more than 100,000 individuals died annually from invasive amoebiasis, was considered as the third cause of death among the parasitic infections after malaria and schistosomiasis (Charles et al, 2004).

Alteration in the concentrations of serum trace elements as Iron, Zinc, and Copper is commonly found in patients with intestinal parasitic infections mainly giardiasis. These trace elements are important micronutrient elements for optimal human metabolic functions including catalytic structural and regulatory activities in which they interact with macromolecules such as enzymes, pro-hormones, and biological membranes. They also play an important role in reproduction, growth, and development of the immune system (Salgueiro et al, 2001). Zinc is the essential element required to maintain the normal physiological function of all forms of life. It is essential for growth, reproductive functions, and glucose metabolism (Ciftci et al, 2003). Copper is an essential trace element that plays an important role in mitochondrial cytochrome oxidase, cytoplasmic superoxide dismutase (SOD), and ceruloplasmin, which are known to have antioxidant functions (Mahboob et al, 2005). 
Iron is a physiologically essential trace element and considered a useful component of cytochromes and oxygen-binding molecules. However, iron is also a biochemically dangerous element. It can damage tissues by catalyzing the conversion of $\mathrm{H}_{2} \mathrm{O}_{2}$ to freeradical ions that attack cellular membrane lipids, proteins, and DNA (Prasad, 2003).

Also, some defense mechanisms that counteract the effect of oxidant radicals which prevent the production of free radicals, decrease their activities, or destroy them need trace elements. The antioxidant Glutathione peroxides contain Selenium, $\mathrm{Cu}$, and $\mathrm{Zn}$, while the superoxide disputes system contains copper and zinc in their structure which diminish the harmful effects of free oxygen radicals. Catalase needs iron as a cofactor as well as ceruloplasmin which is the carrier of $\mathrm{Cu}$. Decreasing these trace elements reduce the action of the antioxidant systems which leads to hyperactivity and inflammation procedures (Schmidt et al., 1996).

The present study aimed to determine the impact of amoebiasis and giardiasis on trace elements among Egyptian children.

\section{Patients and Methods}

A case-control random study was conducted on the patients suffering from gastrointestinal manifestations who attending the outpatient clinics of Pediatrics and Tropical Medicine at $\mathrm{Al}$ Hussein University Hospital, Cairo, Egypt aging (1-18 years), during the period from early September to the end of January 2020. A randomly selected 49 patients suffering from amoebiasis (30 cases) and giardiasis (19 cases) as diagnosed by stool examination as well as Copro-antigen detection was chosen and considered as the infected study group. Another 50 healthy persons, free from intestinal parasites of the same age and gender were chosen and considered as the control group.

Exclusion criteria: included patients below one year as well as above 18 years, nonintestinal protozoal infections, and chronic diseases and did not take vitamins or miner- al supplements for the last 3 months as well as immunocompromised patients.

All children were subjected to the following: 1- A questionnaire filled out by an interview with the patient and/or one of his/her parents or guardians. 2- Fresh stool samples were collected in clean, labeled, and wide-mouthed plastic containers that had tight-fitting overlapping lids. 3-Collection of aseptically $5 \mathrm{ml}$ of venous blood samples using metalfree and stainless-steel needles into appropriately coated tubes (Becton Dickinson Laboratories, Franklin Lakes, NJ, USA) for measurement of serum levels of Zinc, Copper, and Iron, using Atomic Absorption Spectrophotometer according to the manufacturer.

Stool samples were examined macroscopically and microscopically by: 1- Direct wet smear method (Garcia, 2007). 2- Concentration methods by simple floatation and formol ether concentration techniques (Garcia, 2007). 3 - Copro-antigen detection by ELISA was performed using a RIDASCREEN $G i$ ardia and Entamoeba kits (R-Biopharm AG, Darmstadt, Germany). The test was done according to the manufacturer's instructions. Statistical analysis: Data were collected, tabulated and statistically analyzed.

Ethical approval was obtained through the Ethical Committee of Al-Azhar University's Hospitals before the commencement of the study and only patients whose parents/ guardians signed the informed consent were included in the present work.

\section{Results}

The distribution of the chosen protozoal infection among the study group was presented in (Tab.1).

The age distribution among both study and control groups was presented in (Tab. $2 \&$ Fig. 1). Sex and residence distribution were presented in (Tabs. $3 \& 4$ ) while serum trace elements level among both groups was presented in (Tab.5). Statistical comparison of serum trace elements level among both groups was presented in (Tabs. 6, 7, \& 8). 
Table 1: Distribution of the chosen protozoal infection among the study group

\begin{tabular}{|l|c|c|c|}
\hline stage & Amoebiasis group $(\mathrm{n}=30)$ & Giardiasis group $(\mathrm{n}=19)$ & Total Infected Group $(\mathrm{n}=49)$ \\
\hline Cysts & $21(70 \%)$ & $16(84.21 \%)$ & $37(75.51 \%)$ \\
\hline Trophozoites & $4(13.33 \%)$ & $1(5.2 \%)$ & $5(10.20 \%)$ \\
\hline Cysts and Trophozoites & $5(16.66 \%)$ & $2(10.52 \%)$ & $7(14.28 \%)$ \\
\hline
\end{tabular}

Table 2: Age distribution among both study and control groups

\begin{tabular}{|l|l|l|l|l|}
\hline Age Group & Amoebiasis & Giardiasis & Total & Control \\
\hline $1-<3$ & $2(6.7 \%)$ & $1(5.2 \%)$ & $3(6.1 \%)$ & $3(6 \%)$ \\
\hline $3-<6$ & $9(30 \%)$ & $6(31.6 \%)$ & $15(30.6 \%)$ & $14(28 \%)$ \\
\hline $6-<9$ & $9(30 \%)$ & $5(26.3 \%)$ & $14(28.6 \%)$ & $14(28 \%)$ \\
\hline $9-<12$ & $5(16.7 \%)$ & $4(21.1 \%)$ & $9(18.4 \%)$ & $10(20 \%)$ \\
\hline $12-<15$ & $3(10 \%)$ & $2(10.6 \%)$ & $5(10.2 \%)$ & $6(12 \%)$ \\
\hline $15-18$ & $2(6.6 \%)$ & $1(5.2 \%)$ & $3(6.1 \%)$ & $3(6 \%)$ \\
\hline Total & $30(100 \%)$ & $19(100 \%)$ & $49(100 \%)$ & $50(100 \%)$ \\
\hline Mean+SD & $7.47 \pm 3.58$ & $7.32 \pm 3.74$ & $7.41 \pm 3.61$ & $7.58 \pm 3.84$ \\
\hline
\end{tabular}

Table 3: Sex distribution among both groups

\begin{tabular}{|l|c|c|c|c|c|}
\hline Sex & Amoebiasis & Giardiasis & Total infected & Control & P-value \\
\hline Male & $16(53.3 \%)$ & $12(63.2 \%)$ & $28(57.1 \%)$ & $29(58 \%)$ & 1.00 \\
\hline Female & $14(46.7 \%)$ & $7(36.8 \%)$ & $21(42.9 \%)$ & $21(42 \%)$ & 1.00 \\
\hline Total & $30(100 \%)$ & $19(100 \%)$ & $49(100 \%)$ & $50(100 \%)$ & 1.00 \\
\hline
\end{tabular}

Table 4: Residence distribution among both groups

\begin{tabular}{|l|c|c|c|c|c|}
\hline residence & Amoebiasis & Giardiasis & Total infected & Control & P-value \\
\hline Rural & $23(76.7 \%)$ & $16(84.2 \%)$ & $39(79.6 \%)$ & $38(76 \%)$ & 0.95 \\
\hline Urban & $7(23.3 \%)$ & $3(15.8 \%)$ & $10(20.4 \%)$ & $12(24 \%)$ & 0.90 \\
\hline Total & $30(100 \%)$ & $19(100 \%)$ & $49(100 \%)$ & $50(100 \%)$ & 0.94 \\
\hline
\end{tabular}

Table 5: Serum trace elements level among both groups

\begin{tabular}{|l|l|l|l|l|l|l|l|l|}
\hline \multirow{2}{*}{ Trace Elements } & \multicolumn{2}{|l|}{ Amoebiasis $(\mathrm{n}=30)$} & \multicolumn{2}{l|}{ Giardiasis $(\mathrm{n}=19)$} & \multicolumn{2}{l|}{ Total infected $(\mathrm{n}=49)$} & \multicolumn{2}{l|}{ Control Group $(\mathrm{n}=50)$} \\
\cline { 2 - 9 } & Mean & SD & Mean & SD & Mean & SD & Mean & SD \\
\hline $\mathrm{Zn}(\mathrm{mcg} / \mathrm{dl})$ & 65.64 & 8.26 & 68.7 & 9.01 & 66.83 & 8.60 & 95.67 & 8.34 \\
\hline $\mathrm{Cu}(\mathrm{mcg} / \mathrm{dl})$ & 130.63 & 20.17 & 128.81 & 18.75 & 129.93 & 19.45 & 85.07 & 6.29 \\
\hline $\mathrm{Fe}(\mathrm{mcg} / \mathrm{dl})$ & 49.96 & 5.61 & 51.69 & 4.50 & 50.63 & 5.23 & 82.86 & 9.28 \\
\hline
\end{tabular}

Table 6: Statistical comparison of serum zinc level among both groups

\begin{tabular}{|l|l|l|l|}
\hline Comparison & Mean difference & Value of q & P-value $* *$ \\
\hline Amoebiasis vs. Giardiasis & -3.06 & 1.75 & ns $\mathrm{P}>0.05$ \\
\hline Amoebiasis vs. Control group & -30.03 & 21.77 & $\mathrm{P}<0.001$ \\
\hline Giardiasis vs. Control group & -26.96 & 16.75 & $\mathrm{P}<0.001$ \\
\hline Total study group vs. control group & -28.84 & 16.94 & $\mathrm{P}<0.001$ \\
\hline
\end{tabular}

*Tukey-Kramer: If value of q greater than 3.373 then $\mathrm{P}$-value less than $0.05,{ }^{* *} \mathrm{P}$-value $=<0.001$, considered extremely significant. Variation among column means = significantly greater than expected by chance

Table 7: Statistical comparison of serum copper level among both groups

\begin{tabular}{|l|l|l|l|}
\hline Comparison & Mean difference & Value of q & P-value \\
\hline Amoebiasis vs. Giardiasis & 1.82 & 0.60 & ns $\mathrm{P}>0.05$ \\
\hline Amoebiasis vs. Control group & 45.56 & 19.29 & $\mathrm{P}<0.001$ \\
\hline Giardiasis vs. Control group & 43.74 & 15.87 & $\mathrm{P}<0.001$ \\
\hline Total study group vs. control group & 44.85 & 15.49 & $\mathrm{P}<0.001$ \\
\hline
\end{tabular}

Table 8: Statistical comparison of serum Iron level among both groups

\begin{tabular}{|l|l|l|l|}
\hline Comparison & Mean difference & Value of q & $\mathrm{P}$-value \\
\hline Amoebiasis vs Giardiasis & -1.73 & 1.10 & $\mathrm{~ns} \mathrm{P}>0.05$ \\
\hline Amoebiasis vs Control group & -32.90 & 26.61 & $\mathrm{P}<0.001$ \\
\hline Giardiasis vs Control group & -31.16 & 21.60 & $\mathrm{P}<0.001$ \\
\hline Total study group vs control group & -32.23 & 21.22 & $\mathrm{P}<0.001$ \\
\hline
\end{tabular}

\section{Discussion}

Amoebiasis and giardiasis are among the most common intestinal protozoa associated with diarrhea (Boughattas et al, 2017). The Global Burden of Disease Study (GBDS) estimated that amoebiasis was associated with more than 55,000 deaths and 2.2 million disability-adjusted life years (Lozano et $a l, 2012)$. In developed countries, Giardia intestinalis is considered as one of the most common causes of water-borne outbreaks of gastroenteritis. While in developing coun- 
tries, the infection was highly endemic and contributes to malnutrition, which may affect growth and later cognitive function in children (Mørch et al, 2009). The infection was regarded as a serious public health problem, as it causes iron deficiency anemia, micronutrient deficiencies as Zinc, Copper, Magnesium, and Selenium (Simsek et al, 2004).

The present study investigated the impact of amoebiasis and giardiasis on trace elements $(\mathrm{Zn}, \mathrm{Cu}$, and $\mathrm{Fe}$ ) among Egyptian patients where a case-control random study was conducted on 49 patients (1-18 years old) suffering from amoebiasis (30 cases) and giardiasis (19 cases) and considered as the infected study group. Another 50 healthy persons (of the same age), free from intestinal parasites of the same age and gender were chosen and considered as the control group.

Among stool samples of the study group $(n=49), 37$ of them were positive for cysts $(75.51 \%)$ and trophozoites were detected in 5 samples $(10.20 \%)$, while both cysts and trophozoites were detected in 7 samples $(14.28 \%)$. As regard amoebiasis group $(\mathrm{n}=30)$; cysts were detected in 21 samples (70\%) with semi-formed stool, while among loose stool, trophozoites were detected in 4 samples $(13.33 \%)$ and both are detected in 5 samples $(16.66 \%)$.

While, in the giardiasis group $(\mathrm{n}=19)$ cysts were detected in 16 samples $(84.21 \%)$ with semi-formed stool, while in loose stool, trophozoites were detected in one sample $(5.2 \%)$ and both were detected in 2 samples $(10.52 \%)$. These results coincided with Hill (2001) who reported that liquid stool may yield motile trophozoites while semi-formed stool will contain only cysts.

In the present study, the age of the total infected group $(n=49)$ ranged from 1-18 years, the highest level of infection is in the age group $(3-<9$ years) $(59.2 \%)$ and the mean \pm standard deviation of the age was $(7.47 \pm 3.58)$ for amoebiasis group and (7.32 \pm 3.74$)$ for giardiasis group which coin- cided with that obtained by Volotao et al. (2007).

This fact was explained by Culha and Sangün, 2007 who reported that children under 6 years of age are more frequently infected with Giardia lamblia due to immature immune system and frequent exposure to infection. On the other hand, Azazy et al. (2002) stated that giardiasis is commonly seen in children aged 4-12 years in developing countries.

In the present study, the total infected group was 28 were males $(57.1 \%)$ and 21 were females $(42.9 \%)$, in amoebiasis group; 16 were males $(53.3 \%)$ and 14 were females $(46.7 \%)$ and in giardiasis group; 12 were males $(63.2 \%)$ and 7 were females $(36.8 \%)$. Besides, Lucas and Upcroft (2001) found that amoebiasis is more frequent in males than females.

Also, Al-Mekhlafi et al. (2005) reported in their study that giardiasis was more common in males than in females while Lengerich et al. (1994) reported that giardiasis was more common in females than in males. Also, Lebwohl et al. (2003) found the incidence of giardiasis was equal among men and women.

No doubt, the trace elements $(\mathrm{Zn}, \mathrm{Cu}, \mathrm{Fe})$ are vital and essential micronutrients for reproduction, growth, and development with regulatory, immunologic, and antioxidant functions resulting from their action as essential components or cofactors of enzymes throughout metabolism. Low serum levels of these elements could cause impairment in cellular, physiological, and enzymatic functions (Shenkin, 2006).

Zinc is required as a cofactor for the function of intracellular enzymes that may be involved in protein, lipid, and glucose metabolism. It may participate as an integral component of several antioxidant enzymes as a superoxide dismutase enzyme. It is an important element for the immune system, energy production, and absorption of vitamins. So, zinc deficiency can lead to chronic diarrhea in the infants and children Çeliksöz 
et al. (2005).

As regard copper, Wilson (2008) reported in his study that copper is vitally important for the immune system and the nervous system, production of energy in cells as well as the absorption of iron and hemoglobin formation. It has antioxidant function through superoxide dismutase and ceruloplasmin enzymes.

Generally, elevated copper levels are reported in response to infections. This is attributed to changes in the concentration of specific tissue proteins controlled by cytokines (Shenkin, 2006). Turnlund (2006) reported that the most common clinical signs of copper deficiency are anemia, impaired growth, abnormally low numbers of white blood cells a condition that may be accompanied by increased susceptibility to infection and neurological signs.

El Hioui et al. (2008) in their study found that iron was important for hemoglobin synthesis that carries oxygen to all parts of the body, important for the immune system, DNA synthesis and it has antioxidant function through catalase and peroxidases enzymes. They also reported that iron deficiency can exist with or without anemia that can lead to serious health problems, such as poor cognitive, motor development, and behavioral problems in children. Also, recurrent infections and delayed growth.

The exact mechanism of micronutrient deficiency in giardiasis is not clear. Some interacting factors as cytopathic substances are thought to be responsible. Giardia trophozoites attach to the microvillus-covered surface of the duodenum and jejunum. The attachment process damages the microvilli and causes villous atrophy and reduces the gut absorptive capacity (Hawrelak, 2003). The attachment of Giardia lamblia trophozoites by sucking disk to the intestinal epithelium can distort and disrupt microvilli, rapid multiplication of trophozoites can also lead to microvillus, crypt atrophy and affect the activity of digestive enzymes such as lipases, proteases, and disaccharidases which inter- fere with digestion and absorption (Roxström-Lindquist et al, 2006).

In the present study, serum zinc level is significantly decreased in the infected group when compared to the control group. The mean and standard deviation in the total study group was $66.83 \pm 8.60$ (amoebiasis group was $65.64 \pm 8.26$ and giardiasis was $68.71 \pm 9.01$ ) but in the control group was $95.67 \pm 8.34$. Statistical comparison of serum Zinc by One-way Analysis of Variance (ANOVA) test shows that $\mathrm{P}$-value is < 0.001 , considered extremely significant.

This may be due to dietary factors (intake of food low in antioxidant) so the body will use endogenous superoxide dismutase (SOD) to scavenge the overproduction of reactive oxygen species as a result of parasitic infection which leads to decrease serum zinc level. Also, it could be due to the antioxidant effect of zinc which plays a structural role in the maintenance of $\mathrm{Cu}-\mathrm{Zn}$-SOD structural integrity Çeliksöz et al. (2005).

Also, Demicri et al. (2003) showed that serum zinc level was significantly decreased in giardiasis when compared to controls which may be due to poor absorption.

Nevertheless, Kiliç et al. (2003) and Çulha and Sangün (2007) did not find any significant difference in zinc levels in patients with giardiasis compared to controls.

As zinc is not stored in the body in large amounts, serum zinc levels could easily decline during infections in children with low zinc intake (Yones et al., 2015).

As regards copper, in the present study, the serum level was significantly increased in the infected study group when compared to the control group.

The mean and standard deviation in the total study group was $129.93 \pm 19.45$ (amoebiasis group was $130.63 \pm 20.17$ and giardiasis was $128.81 \pm 18.76$ ), but in the control group was $85.07 \pm 6.29$. Statistical comparison of serum zinc by One-way Analysis of Variance (ANOVA) test shows that $\mathrm{P}$-value is < 0.001 , considered extremely significant. The significant increase in the serum level of 
copper demonstrates that inflammation initiates free radical generation.

This may be explained by the antagonistic effect of zinc and zinc deficiency in a patient with parasitic infection and increase copper absorption by the gastrointestinal tract. Zinc antagonize copper absorption by inducing the synthesis of thionine, which have a higher affinity to copper than zinc (Emerit et al, 2001). Similarly, Ertan et al. (2002) have studied a total of 45 children aged between 2 and 14 years. They found that giardiasis increased the serum level of copper due to undulating levels of ceruloplasmin during infections. The study done by Eckersall and Conner (1988) stated that ceruloplasmin may be involved in the transfer of copper into cells, or as an antioxidant, as it is the major extracellular scavenger of oxygenderived free radicals secreted by phagocytes. Ceruloplasmin level increased during infections, in $50 \%$ only of cases, and no increases at all found in some conditions where other reactants have increased.

However, Karakas et al. (2001) studied the serum copper in a total of 20 Turkish children with giardiasis, and 20 healthy children were selected as control. They showed that serum $\mathrm{Cu}$ levels were not significantly differed when compared to control. They stated that absorption of $\mathrm{Cu}$ through the whole small intestine and to a lesser extent through large intestine may be responsible, in addition to lower recommended dietary intake about $0.9 \mathrm{mg} /$ day which is very close to the lower limit of $1 \mathrm{mg} /$ day found in the diet. Also, Demicri et al. (2003) and Çulha and Sangün (2007) have investigated the level of $\mathrm{Cu}$ in chronic giardiasis and they found that there was no significant difference in copper between giardiasis and control groups. They stated that a small amount of $\mathrm{Cu}$ absorbed by skin and inhalation also the intestinal absorption of $\mathrm{Cu}$ varies with dietary intake, so it increased with low intakes of $\mathrm{Cu}$ and lowered with high intakes of it.

One of the main influences of infections in the hemopoietic system is concerning iron metabolism. Malabsorption related iron deficiency is expected in patients with giardiasis, which could be protective considering the role of iron in the formation of the hydroxyl radical. However, asymptomatic giardiasis did not affect the intestinal absorption of iron and the hemoglobin response to oral iron therapy in a study conducted with iron-deficient anemic children aged between 1- and 6-years-old.15 Iron deficiency in patients with giardiasis could be treated successfully by anti-giardia compounds, not with iron supplementation (Taneli et al, 1994).

As regards Iron, in the present study, serum iron $(\mathrm{Fe})$ level was significantly decreaased in infected study groups when compared to the control group. The mean and standard deviation in the total study group was $50.63 \pm 5.23$ (amoebiasis group was $49.96 \pm$ $5.61 \&$ giardiasis was $51.69 \pm 4.50$ ) but in the control group was $82.87 \pm 9.28$. The statistical comparing of serum Zinc by (ANOVA) showed $(\mathrm{P}-=<0.001)$, considered extremely significant. There is a significant difference between all studied groups and the control group, but no significant difference statistically between the amoebiasis and giardiasis groups.

Also, Demicri et al. (2003) have tested serum Iron level among 34 children with chronic giardiasis and were compared with controls. They found that there was a significant difference in Iron between giardiasis and control groups. They stated that malabsorption was responsible for this and it was evidenced by finding no change in serum levels of Fe after oral intake of Fe supplements in giardiasis group. Also, Ertan et al. (2002) found that giardiasis significantly lowered the serum levels of $\mathrm{Fe}$ in the infected group than in the control group due to malabsorption. Also, Çulha and Sangün (2007) found there was a significant difference in Fe levels between the infected group with giardiasis and the control group.

However, Saba Adnan et al. (2009) have studied one hundred patients with parasitic infections (35 patients with toxoplasmosis, 
32 patients with leishmaniasis, 24 patients with amoebiasis and 9 patients with giardiasis) while 130 were a control group. children, they found a significant increase in the serum level of the Iron inpatient group as compared with control subjects. This difference may be due to erythrocytes degradation after phagocytosis, also the release of ferritin into circulation (Salgueiro et al 2001).

\section{Conclusion}

The intestinal protozoal infection is an important cause of malabsorption in children. It can elevate serum copper levels and decrease serum zinc and iron levels. Low serum zinc is associated with a decline in lymphocyte and thymus functions, while iron deficiency can cause significant impairments in the hemopoietic system.

Consequently, it is essential to do properdiagnose and treat pediatric patients to prevent potential damages to child growth and health.

\section{References}

Al-Mekhlafi, MS, Azlin, M, Nor Aini, U, Shaik, A, Ismail, MG, et al. 2005: Giardiasis as a predictor of childhood malnutrition in Orang Asli children in Malaysia. Trans. R. Soc. Trop. Med. Hyg. 99:686-91.

Azazy, AA, Al-Mahbashi, TY, Al-Mekhlafi, H M, 2002: Prevalence of intestinal and blood parasites among school children in Sana'a and AlMahweet Provinces, Yemen. Yemen Med. J. 4: 50-5.

Boughattas, S, Behnke, J,Al-Ansari, K, Aarti Sharma, A, Abu-Alainin, W, et al, 2017: Molecu-lar analysis of the enteric protozoa associated with acute diarrhea in hospitalized children. Front Cell Infect. Microbiol, 2, 7:343-8

Castillo-Duran, C, Vial P, Uauy, R, 1983: Trace mineral balance during acute diarrhea in infants. J. Pediat.113:452-7.

Çeliksöz, A, Değerli, S, Çinar, Z, Erandaç, M, 2005: Effects of giardiasis among school children in Turkey on success, weight, and height indices. Pediatr. Inter. 47:567-71.

Charles, R, Sterlin, A, Rodney, D, 2004: The pathogenic enteric protozoa: Giardia, Entamoeba, Cryptosporidium, and Cyclospora; Kluwer Academic Publishers, Bostonhttp:// kluweronline.com.
Ciftci, TU, Ciftci, B, Yis, O, 2003: Changes in serum Selenium, Copper, Zinc levels, and $\mathrm{Cu} / \mathrm{Zn}$ ratio in patients with pulmonary tuberculosis during therapy. Biol. Trace Elem. Res. 95:65-71. Çulha, G, Sangün, MK, 2007: Serum levels of zinc, copper, iron, cobalt, magnesium, and selenium elements in children diagnosed with Giardia intestinalis and Enterobius vermicularis in Hatay. Turkey. Biol. Trace Elem. Res. 118:21-6. Demicri, M, Delibas, N, Altuntas, I, Oktem, F, Yönden, Z, 2003: Serum iron, zinc and copper levels and lipid peroxidation in children with chronic giardiasis. J. Hlth. Popul. Nutr. 21, 1:725.

Eckersall, PD, Conner, JG, 1988: Bovine and canine acute-phase proteins. Vet. Res. Commun. 12:169-78.

El Hioui, M, Ahami, AO, Aboussaleh, Y, Rusinek, S, Dik, K, et al. 2008: Iron deficiency and anaemia in rural school children in a Coastal Area of Morocco. Pakist. J. Nutrit. 7, 3:400-3.

Emerit, J, Beaumont, C, Trivin, F, 2001: Iron metabolism, free radicals, and oxidative injury. Biomed. Pharmacother. 55, 6:333-9

Ertan, P, Yereli, K, Kurt, O, Balcioğlu, IC, Onag, A, 2002: Serological levels of Zinc, Copper, and Iron elements among Giardia lamblia infected children in Turkey. Pediatr. Inter. 44: 286-8.

Garcia, LS, 2007: Intestinal Protozoa: Flagellates and Ciliates. In: Diagnostic Medical Parasitology $\left(5^{\text {th }}\right.$ ed.); ASM Press American Society for Microbiology.

Hawrelak, JA, 2003: Giardiasis. Alterna. Med. Rev. 8, 2:129-41.

Hill, DR, 2001: Giardia lamblia. In: Principles and Practice of Clinical Parasitology. Gillespie, S. and Pearson, R.D. (eds.); Wiley Press, Ltd.

Karakaș, Z, Demirel, N, Tarakçioğlu, M, Mete, N, 2001: Serum Zinc and Copper levels in Southeastern Turkish children with giardiasis or amebiasis. Biol. Trace Elem. Res. 84:11-8.

Kiliç, E, Yazar, S, Saraymen, R, 2003: Responsiveness of total content changes of Magnesium and Zinc status in patients infected with $\mathrm{Gi}_{-}$ ardia intestinalis. Biol. Trace Elem. Res. 961538.

Lebwohl, B, Deckelbaum, RJ, Green, PH, 2003: Giardiasis. Gastrointest. Endo. 57:906-13. Lengerich, EJ, Addiss, DG, Juranek, DD, 1994: Severe giardiasis in the United States. Clin. Infect. Dis. 18:760-3. 
Lozano, R, Naghavi, M, Foreman, K, et al. 2012: Global and regional mortality from 235 causes of death for 20 age groups in 1990 and 2010: a systematic analysis for the Global Burden of Disease Study 2010. Lancet 380:2095128.

Lucas, R, Upcroft, J, 2001: Clinical significance of the redefinition of the agent of amoebiasis. Rev. Latinoam. Microbiol. 43, 4:183-7.

Mahboob, M, Rahman, MF, Grover, P, 2005: Serum lipid peroxidation and antioxidant enzyme levels in male and female diabetic patients. Singapore Med. J. 46, 7:322-4.

Mørch, K, Hanevik, K, Rortveit, G, Wensaas, KA, Langeland, N, 2009: High rate of fatigue and abdominal symptoms 2 years after an outbreak of giardiasis. Trans. R. Soc. Trop. Med. Hyg. 103:530-2.

Pennard, A, Ervin, M, Talavera, F, Sheridan, BJ, Halamka, JD et al. 2008: Giardiasis. Https ://EMERG/Topic 215.htm.www.emedicine.com. Prasad, AS, 2003: Zinc deficiency has been known for 40 years but ignored by global health organizations. BMJ. 326:409-10.

Roxström-Lindquist, K, Palm, D, Reiner, D, Ringqvist, E, Svärd, SG, 2006: Giardia immunity an update. Trend. Parasitol. 22, 1:27-31.

Saba, AA, Nadham, KM, Jawad, KM, 2009: Trace elements levels in patients with some different parasitic infections. JBMS 21, 4:27-35

Salgueiro, MJ, Krebs, N, Zubillaga, MB, 2001: Zinc and diabetes. Biol. Trace Elem. Res. 81: 215-28.

Schmidt, KN, Amstad, P, Cerutti, P, 1996:
Identification of hydrogen peroxide as the relevant messenger in the activation pathway of transcription factor NF-Kappan. Adv. Exp. Med. Biol. 387:63-8.

Shenkin, A, 2006: Micronutrients in health and disease. Postgrad Med J; 82: 559-67.

Simsek, Z, Yildiz-Zeyrek, F, Kurcer, MA, 2004: Effect of Giardia infection on growth and development on children aged 0-5 years. J. Trop. Pediatr. 50, 2:90-3.

Taneli, N, Anal, Ö, Erdem, N, Töre, R, Güner, G, 1994: Free radical collection insufficiency due to giardiasis in children. Acta Parasitol. Turcica 18:6-12

Turnlund, JR, 2006: Copper. In: Shils, ME, Shike, M, Ross, AC, Caballero, B, Cousins, RJ, (eds) Modern Nutrition in Health and Disease. $10^{\text {th }}$ ed. Philadelphia: Lippincott Williams \& Wilkins.

Volotao, AC, Costa-Macedo, LM, Haddadc, FS, Brandao, A, Peralta, JM, et al. 2007: Genotyping of Giardia duodenalis from human and animal samples from Brazil using giardin gene: A phylogenetic analysis. Acta Trop. 102:10-9.

Wilson, L, 2008: Copper toxicity syndrome. At http://www.drlwilson.com/Articles/copper history. htm.

Yones, DA, Galal, LA, Abdallah, AM, Zaghlol, KS, 2015: Effect of enteric parasitic infection on serum trace elements and nutritional status in upper Egyptian children. Trop. Parasitol. 5, 1:29-35.

Explanation of figure

Fig. 1: Age distribution among infected group

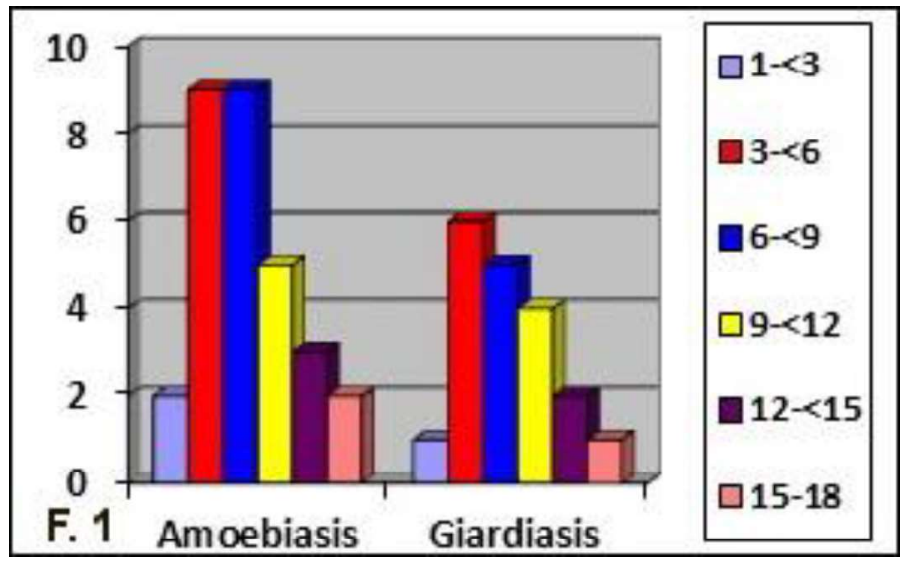

